\title{
Folate status and health behaviours in two Australian Indigenous populations in north Queensland
}

\author{
Ming Li ${ }^{1, *}$, Robyn McDermott ${ }^{1}$, Katina $\mathrm{D}^{\prime} \mathrm{Onise}^{1}$ and Dympna Leonard ${ }^{2}$ \\ 'Sansom Institute for Health Research, University of South Australia, CEA-01, City East Campus (P4-15C), \\ GPO Box 2471, Adelaide, SA 5001, Australia: ${ }^{2}$ Cairns Public Health Unit, Tropical Regional Services, \\ Queensland Health, Cairns, QLD, Australia
}

Submitted 8 September 2011: Accepted 13 December 2011: First published online 10 February 2012

\begin{abstract}
Objective: To assess nutritional status using red-cell folate (RCF) and associated health behaviours including fruit and vegetable intake, smoking, drinking and physical activity in two Indigenous populations living in remote northern Australia. Design: A cross-sectional survey conducted during 1998-2000.

Setting: Twenty-six rural communities in north Queensland, Australia.

Subjects: A total of 2524 Indigenous people aged 15 years and over was included in the study. Self-reported fruit and vegetable intake, tobacco smoking, alcohol intake and physical activity were recorded. RCF was measured using the Bayer Advia Centaur automated immunoassay system. The association between low $\mathrm{RCF}(\mathrm{RCF}<295 \mathrm{nmol} / \mathrm{l})$ and risk factors was analysed using general linear models adjusted for demographic factors and covariates, namely BMI, diabetes and dyslipidaemia.

Results: The prevalence of RCF deficiency was higher in Aboriginal participants compared with Torres Strait Islanders $(25.6 \% v$. 14.8\%, $P<0 \cdot 001)$. Young women of childbearing age were more likely to have low RCF. Among Aboriginal adults, smoking was strongly associated with low RCF (risk ratio $=1 \cdot 9,95 \%$ CI $1 \cdot 5,2 \cdot 5$ in females and risk ratio $=2 \cdot 9,95 \%$ CI $1 \cdot 9,4 \cdot 2$ in males).

Conclusions: Indigenous Australians, especially women of childbearing age, had high prevalence of low RCF. Smoking was associated with insufficient folate independent of fruit and vegetable intake and alcohol consumption in the Aboriginal population. This population with an already higher risk of obesity and higher rate of tobacco smoking should be targeted to improve nutrition status to prevent ill health such as diabetes and CVD.
\end{abstract}

Keywords

Folate

Behavioural factors Indigenous adults
Folate is an essential micronutrient found in a range of foods but is highest in green leafy vegetables, citrus fruits, nuts, lentils and liver. A nutritious diet rich in the $\mathrm{B}$ vitamins and vitamin $\mathrm{C}$ is generally rich in folate ${ }^{(1)}$, so folate can be an indicator of the general nutritional quality of the diet. The significance of folate deficiency in an array of diseases is the subject of increasing investigation. While the causal role of folate deficiency in the development of neural tube defects has been well described ${ }^{(2)}$, maternal low folate status is also associated with low birth weight and/or preterm birth $^{(3)}$. More recently folate deficiency has been identified as an independent risk factor for $\mathrm{CVD}^{(4,5)}$, as well as breast cancer ${ }^{(6)}$ and colorectal cancer ${ }^{(7,8)}$. The role of folate in CVD may not be directly causal, whereas it is hypothesised that the effect on neural tube defects and cancer is through direct disruption of DNA synthesis ${ }^{(9)}$.

A number of risk factors for folate deficiency have been identified. Lifestyle factors such as fruit and vegetable intake, smoking tobacco and drinking alcohol have been associated with red-cell folate (RCF) concentration ${ }^{(9-13)}$. Both smoking and high levels of alcohol consumption may lead to folate deficiency through an associated poorer quality diet. There may also be direct toxic effects that lead to folate deficiency in smokers, whereby substances in tobacco block the synthesis of folate and also induce inflammatory responses that potentially disrupt hepatic pyridoxine metabolism ${ }^{(9)}$. Alcohol may also have a direct effect on folate levels by impairing intestinal folate absorption, impairing hepatic uptake and metabolism of folate and increasing the renal excretion of folate, in addition to oxidative destruction of folate ${ }^{(12)}$. Given the known clustering of these health behaviours and the potential for direct toxic effects on folate absorption, synthesis, metabolism and excretion, it is likely that there is a complex interplay of these factors on folate levels.

Aboriginal and Torres Strait Islander people (hereafter referred to as 'Indigenous') are socio-economically disadvantaged groups who have a higher prevalence of 
behaviours such as smoking, high-risk alcohol intake and insufficient consumption of fruit and vegetables compared with other Australians ${ }^{(14)}$, all of which may contribute to folate deficiency and its concomitant risks. National data have shown that the prevalence of neural tube defects in Indigenous women is double that in nonIndigenous women $(9 \cdot 1 v \cdot 4 \cdot 4 \text { per } 10000 \text { births })^{(15)}$. There have been few studies of folate status that have been conducted in representative populations, and no studies in representative Indigenous populations. Furthermore, given the use of different assays and reference ranges, it is difficult to compare studies directly that have occurred in different countries and populations ${ }^{(16)}$. Therefore the purpose of the present study was to document the folate status assessed by RCF in a representative population of Indigenous Australians and to evaluate the potential role of health behaviours (smoking, drinking, fruit and vegetable intake, physical activity) in folate deficiency. RCF was measured as this is thought to reflect long-term folate status better than the alternative serum folate ${ }^{(17)}$.

\section{Methods}

\section{Study participants}

The Well Persons Health Check, conducted between 1998 and 2000, offered screening and referral services for people in discrete Indigenous communities in northern Queensland $^{(18)}$. Briefly, all Indigenous residents of the communities aged 13 years and over were invited to participate through printed media, local radio and word of mouth via the local health service, community council and community groups. Based on the local census data, the study achieved a participation rate of $44.5 \%$ with greater participation noted in smaller communities ${ }^{(18)}$. In total, 2524 Indigenous people aged 15 years and over with RCF measurements were included in the present study. The study was approved by the Cairns Base Hospital Ethics Committee with support from relevant peak Aboriginal and Torres Strait Islander Health Councils.

\section{Measurements}

Fruit and vegetable intake was assessed using a methodology derived from that used in the National Nutrition Survey $1995^{(19)}$. The number of servings of fruit and vegetables consumed in the $24 \mathrm{~h}$ prior to the survey was recorded, using a pictorial guide to illustrate servings. A serving was defined as one piece of fruit, half a cup of vegetables or one cup of salad. Physical activity was measured using a $7 \mathrm{~d}$ recall method in which participants were asked to report daily physical activities of at least 30 min duration and moderate intensity performed during the week before their health check. Alcohol intake was recorded and those who drank alcohol were asked to recall the types and quantities of alcohol consumed in the previous $7 \mathrm{~d}$. Smoking status was recorded and current smokers were asked how many cigarettes they smoked daily. The physical activity, smoking and alcohol intake measures have been used widely in other studies ${ }^{(20-22)}$. Physical activity was categorised using the WHO criteria in which 'enough' means doing moderate to vigorous physical activity for more than $30 \mathrm{~min} / \mathrm{d}$ for $5 \mathrm{~d}$ in the week before the survey ${ }^{(23)}$.

Participants were asked to remove footwear and heavy clothing and were weighed to the nearest $0 \cdot 1 \mathrm{~kg}$. Height was recorded to the nearest centimetre. BMI $\left(\mathrm{kg} / \mathrm{m}^{2}\right)$ was calculated as weight (in kilograms) divided by the square of height (in metres) and categorised by using the WHO definition of overweight and obesity ${ }^{(23)}$. Recorded blood pressure was the average of three measurements taken over the course of the health check.

Fasting venous blood specimens were collected by trained health staff and the following biochemical measures were assessed: RCF, total cholesterol, HDL cholesterol, TAG and glucose. Blood was collected in a $4 \mathrm{ml}$ vacuum tube containing EDTA and an $8 \mathrm{ml}$ vacuum tube without anticoagulant. The latter was spun for $10 \mathrm{~min}$ in a portable centrifuge within $1 \mathrm{~h}$ of collection. Blood tubes were sealed, packed in refrigerated containers and transported by air to the laboratory. RCF was measured using the Bayer Advia Centaur automated immunoassay system (Bayer, Australia) by Queensland Health Pathology Service in Brisbane. The reference range for this assay is 295-1800 nmol/1, with low RCF defined as less than $295 \mathrm{nmol} / \mathrm{l}$. Diabetes was defined using the WHO criteria $^{(24)}$ and dyslipidaemia was defined according to the Australian Diabetes Society ${ }^{(25)}$.

\section{Analysis}

All analyses were undertaken using the STATA statistical software package version $10 \cdot 1$ (StataCorp, College Station, TX, USA). Our previous study indicated that Aboriginal adults had a different health and behavioural profile from Torres Strait Islanders ${ }^{(26)}$, so the analysis was stratified by ethnicity. Descriptive analysis of the basic characteristics of the two populations was conducted. The mean RCF differences by age, BMI categories, dyslipidaemia, diabetes and behavioural factors in men and women were compared using the Student $t$ test or one-way ANOVA. The association between RCF deficiency and fruit and vegetable intake, smoking and drinking was studied using generalised linear models with a binomial distribution and log function, adjusted for age in both populations, and the risk ratio (RR) was reported. Fruit and vegetable intake was categorised into three subgroups by using the daily number of servings ( $\leq 1$ serving/d, 2-3 servings/d, $\geq 4$ servings/d). A potential dose-response effect of smoking was explored using daily cigarette number analysed in quartiles. The interaction of smoking and alcohol drinking was also explored by creating categories as 'none of the two', 'smoking only', 'drinking only' and 'both smoking and drinking'. The possible mediating effect of smoking on 
the association of fruit and vegetable intake and low RCF was studied by adding smoking to the model of fruit and vegetable intake adjusted for age and sex and comparing the change in risk ratios. The independent associations of behavioural factors were also adjusted for covariates, namely BMI, diabetes and dyslipidaemia. The level of statistical significance was set as $P<0 \cdot 05$.

\section{Results}

Among a total of 2524 participants who had RCF measurements aged over 15 years, 1580 (62.6\%) were Aboriginal people and 1310 (51.9\%) were women. The mean RCF was $398 \cdot 6 \mathrm{nmol} / 1$ (sD $158 \cdot 2$, ranging from 20 to $1306 \mathrm{nmol} / \mathrm{l})$ in Aboriginal adults compared with a mean $440 \cdot 5 \mathrm{nmol} / \mathrm{l}$ (SD $159 \cdot 7$, ranging from 107 to $1609 \mathrm{nmol} / \mathrm{l}$ ) in Torres Strait Islanders. Table 1 shows some basic population characteristics. Self-reported prevalence of tobacco smoking, drinking alcohol and physical inactivity was higher in Aboriginal adults than Torres Strait Islanders, while Torres Strait Island adults had higher BMI and blood glucose level. The prevalence of low RCF was higher among Aboriginal people (25.6\%, 95\% CI 23.4, 27.7\%) compared with Torres Strait Islanders $(14 \cdot 8 \%, 95 \%$ CI $12 \cdot 6,17 \cdot 1 \%)$.

Table 2 shows the mean RCF by age group, BMI and lifestyle factors for men and women. Younger women had lower mean RCF than older women. Overweight Aboriginal adults had higher RCF than those with BMI below $25 \mathrm{~kg} / \mathrm{m}^{2}$. Further analysis indicated that Aboriginal adults with higher BMI had significantly more servings of vegetables and were less likely to smoke than those with a normal BMI. Adults with diabetes seemed to have higher RCF in both groups and this association was confounded by age. Smokers had significantly lower RCF regardless of ethnicity and sex. The mean RCF was higher among Aboriginal women with more than two servings of fruit daily and in Aboriginal men having more than four servings of vegetables daily. Among Torres Strait Islanders, neither fruit intake nor vegetable intake appeared to be associated with RCF. Dyslipidaemia and self-reported physical activity were not associated with RCF in the two populations (data not shown).

Table 3 shows the association between fruit and vegetable intake, smoking and drinking and low RCF $(<295 \mathrm{nmol} / \mathrm{l})$ after adjustment for age in the Indigenous populations. Female Aboriginal smokers had double the risk of low RCF compared with non-smokers $(\mathrm{RR}=1 \cdot 9$, $95 \%$ CI $1 \cdot 5,2 \cdot 5)$. Aboriginal men smokers had three times the risk ( $\mathrm{RR}=2 \cdot 9,95 \% \mathrm{CI} 1 \cdot 9,4 \cdot 2)$. There appeared to be no dose effect of numbers of cigarettes on RCF levels. Smoking was associated with low RCF independently of drinking status. Alcohol drinking alone was not associated with low RCF. Further analyses were conducted on the effect of low, moderate or high alcohol intake on RCF

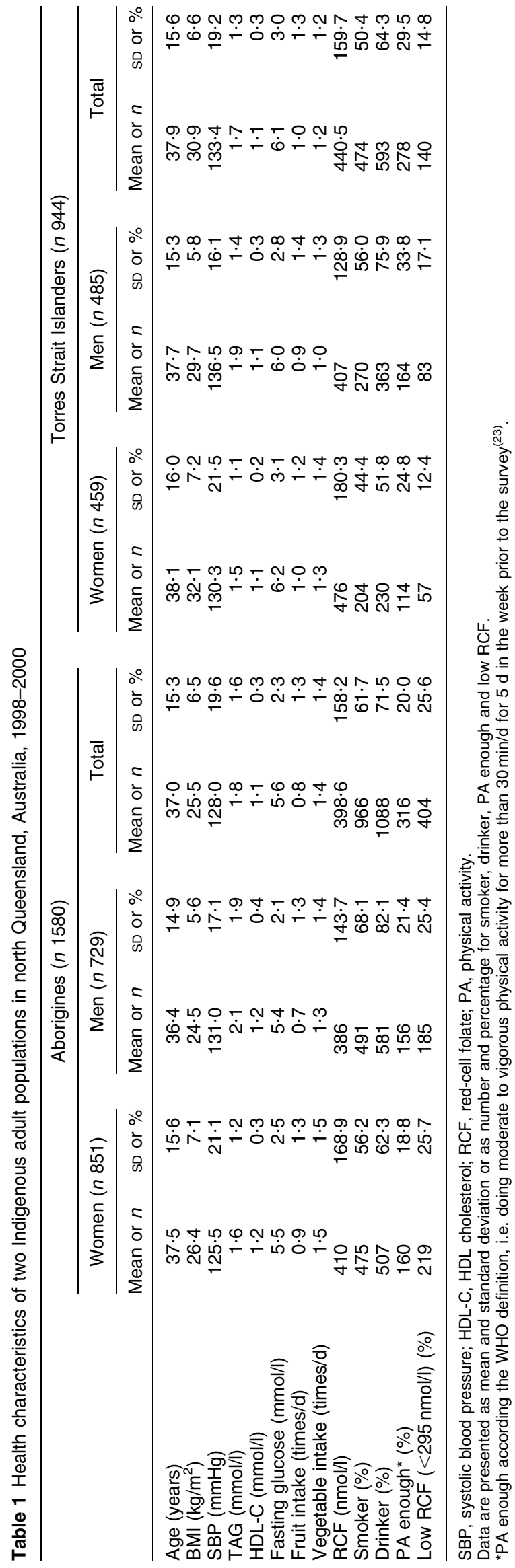


Table 2 Mean RCF (nmol/l) by population characteristics in two Indigenous adult populations in north Queensland, Australia, 1998-2000

\begin{tabular}{|c|c|c|c|c|c|c|c|c|c|c|c|c|c|c|c|c|}
\hline \multirow{3}{*}{$\begin{array}{l}\text { Population } \\
\text { characteristic }\end{array}$} & \multicolumn{8}{|c|}{ Aborigines ( $n$ 1580) } & \multicolumn{8}{|c|}{ Torres Strait Islanders ( $n$ 944) } \\
\hline & \multicolumn{4}{|c|}{ Women $(n 851)$} & \multicolumn{4}{|c|}{ Men $(n 729)$} & \multicolumn{4}{|c|}{ Women ( $n$ 459) } & \multicolumn{4}{|c|}{ Men ( $n$ 485) } \\
\hline & $n$ & Mean & $95 \% \mathrm{Cl}$ & $P$ & $n$ & Mean & $95 \% \mathrm{Cl}$ & $P$ & $n$ & Mean & $95 \% \mathrm{Cl}$ & $P$ & $n$ & Mean & $95 \% \mathrm{Cl}$ & $P$ \\
\hline \multicolumn{17}{|l|}{ Age (years) } \\
\hline $15-24$ & 203 & 366 & 347,385 & \multirow[t]{3}{*}{$<0.01$} & 179 & 393 & 371,414 & \multirow[t]{3}{*}{$0 \cdot 71$} & 108 & 465 & 431,500 & \multirow[t]{3}{*}{$<0.01$} & 118 & 407 & 384,430 & \multirow[t]{3}{*}{$0 \cdot 20$} \\
\hline $25-44$ & 389 & 411 & 395,428 & & 349 & 382 & 367,397 & & 206 & 448 & 427,470 & & 212 & 397 & 380,413 & \\
\hline$\geq 45$ & 259 & 440 & 418,464 & & 201 & 387 & 366,408 & & 145 & 523 & 490,556 & & 155 & 421 & 399,443 & \\
\hline \multicolumn{17}{|l|}{$\mathrm{BMI}\left(\mathrm{kg} / \mathrm{m}^{2}\right)$} \\
\hline$<25.0$ & 393 & 382 & 366,398 & \multirow[t]{3}{*}{$<0.01$} & 433 & 367 & 354,381 & \multirow[t]{3}{*}{$<0.01$} & 75 & 452 & 416,487 & \multirow[t]{3}{*}{0.36} & 101 & 382 & 360,404 & \multirow[t]{3}{*}{0.06} \\
\hline $25 \cdot 0-29 \cdot 9$ & 233 & 413 & 392,434 & & 169 & 392 & 372,413 & & 107 & 490 & 455,525 & & 173 & 410 & 390,430 & \\
\hline$\geq 30 \cdot 0$ & 222 & 452 & 428,477 & & 125 & 445 & 419,471 & & 276 & 476 & 454,498 & & 208 & 418 & 400,437 & \\
\hline \multicolumn{17}{|l|}{$\begin{array}{l}\text { Fruit intake } \\
\text { (servings/d) }\end{array}$} \\
\hline$\leq 1$ & 637 & 394 & 382,407 & \multirow[t]{3}{*}{$<0.01$} & 573 & 385 & 373,396 & \multirow[t]{3}{*}{$0 \cdot 87$} & 319 & 479 & 458,500 & \multirow[t]{3}{*}{0.83} & 359 & 404 & 391,416 & \multirow[t]{3}{*}{$0 \cdot 42$} \\
\hline $2-3$ & 167 & 458 & 429,486 & & 115 & 391 & 361,421 & & 124 & 469 & 441,496 & & 94 & 420 & 390,451 & \\
\hline$\geq 4$ & 46 & 448 & 398,497 & & 39 & 393 & 353,432 & & 16 & 463 & 369,557 & & 30 & 423 & 377,470 & \\
\hline \multicolumn{17}{|c|}{$\begin{array}{l}\text { Vegetable intake } \\
\text { (servings/d) }\end{array}$} \\
\hline$\leq 1$ & 442 & 406 & 390,422 & \multirow[t]{3}{*}{0.50} & 454 & 372 & 360,385 & \multirow[t]{3}{*}{$<0.01$} & 275 & 475 & 453,498 & \multirow[t]{3}{*}{0.33} & 329 & 405 & 391,418 & \multirow[t]{3}{*}{$0 \cdot 76$} \\
\hline $2-3$ & 340 & 410 & 393,428 & & 223 & 406 & 386,426 & & 150 & 467 & 441,494 & & 131 & 414 & 391,436 & \\
\hline$\geq 4$ & 68 & 431 & 389,474 & & 50 & 422 & 371,473 & & 34 & 518 & 459,577 & & 22 & 414 & 343,485 & \\
\hline \multicolumn{17}{|l|}{ Smoking } \\
\hline No & 371 & 468 & 449,487 & $<0.01$ & 230 & 448 & 428,468 & $<0.01$ & 255 & 499 & 476,522 & $<0.01$ & 212 & 428 & 410,446 & $<0.01$ \\
\hline Yes & 475 & 363 & 351,376 & & 491 & 356 & 345,367 & & 204 & 447 & 424,470 & & 270 & 391 & 376,404 & \\
\hline Drinking & & & & & & & & & & & & & & & & \\
\hline No & 307 & 423 & 403,442 & 0.05 & 127 & 399 & 368,430 & $0 \cdot 13$ & 214 & 494 & 468,520 & 0.05 & 115 & 406 & 381,432 & 0.98 \\
\hline Yes & 507 & 398 & 384,412 & & 581 & 378 & 368,389 & & 230 & 460 & 438,482 & & 363 & 406 & 393,419 & \\
\hline
\end{tabular}

$\mathrm{RCF}$, red-cell folate.

The $t$ test or one-way ANOVA was conducted separately in women and men in each Indigenous group to compare mean RCF by population characteristics.

and showed no difference with the results presented here (data not shown). The direction of association was in the expected direction across all fruit and vegetable categories, although for many the $95 \%$ confidence interval included the null. Aboriginal men reporting two or more servings of vegetables daily were $40 \%$ less likely to have low RCF regardless of age $(\mathrm{RR}=0 \cdot 6,95 \% \mathrm{CI} 0 \cdot 4$, $0 \cdot 8$ ), and this effect was attenuated slightly after adjustment for smoking ( $\mathrm{RR}=0 \cdot 8,95 \% \mathrm{CI} 0 \cdot 5,0 \cdot 9)$. The association of low RCF with smoking in Aboriginal women and men and with vegetable intake in Aboriginal men was independent of BMI, diabetes and dyslipidaemia.

\section{Discussion}

The present study is the first to assess RCF status in Indigenous populations in north Queensland and to explore the lifestyle factors that are associated with RCF deficiency. There was a high prevalence of folate deficiency in both Aboriginal and Torres Strait Islanders, particularly for Aboriginal women of childbearing age. A low RCF was associated with smoking after adjustment for fruit and vegetable intake in Aboriginal people and possibly Torres Strait Islanders, although small sample sizes limited the precision of the latter estimate.

The prevalence of RCF deficiency (20.0\%) was far higher than among Australian non-Indigenous adults aged 25 years and over using comparable baseline data from the Australian Diabetes, Obesity and Lifestyle Study (AusDiab) in 1999-2000, which showed a $2.5 \%$ prevalence of folate deficiency in the Queensland population (internal analysis, data not shown). This tracks with disadvantage across a range of socio-economic indicators including education, employment, income and housing ${ }^{(27)}$. The food intake data among 8883 adults aged 18-61 years using $24 \mathrm{~h}$ recall methods collected from the 1995 Australian National Nutrition Survey showed participants from lowincome households consumed a smaller amount of fruit and vegetables and those that were consumed were lower in folate ${ }^{(28)}$.

There may have been a reduction in the prevalence of folate deficiency since the introduction of mandatory fortification of wheat flour for bread making in September 2009, after the data for the present study were collected $^{(29)}$. A study evaluating the impact of the Australian voluntary folate fortification policy from 1995 to 2001 found that among 468 adults aged 27-77 years randomly selected in Perth, Western Australia, the serum folate level increased significantly (38\%) after the policy especially among those who consumed at least one fortified food ${ }^{(30)}$. Evidence from the USA, Canada and other countries with mandatory folic fortification programmes showed a substantial reduction in incidence of birth defects and increases in serum folate and RCF concentrations ${ }^{(31)}$. A recent report from Canada showed the prevalence of low RCF was $1 \%{ }^{(32)}$. 
Table 3 The association of low RCF (<295 nmol/l) with fruit and vegetable intake, smoking and drinking in two Indigenous adult populations in north Queensland, Australia, 1998-2000

\begin{tabular}{|c|c|c|c|c|c|c|c|c|c|c|c|c|c|c|c|c|}
\hline \multirow[b]{3}{*}{ Risk factor } & \multicolumn{8}{|c|}{ Aborigines } & \multicolumn{8}{|c|}{ Torres Strait Islanders } \\
\hline & \multicolumn{4}{|c|}{ Women } & \multicolumn{4}{|c|}{ Men } & \multicolumn{4}{|c|}{ Women } & \multicolumn{4}{|c|}{ Men } \\
\hline & $\begin{array}{c}\text { Crude } \\
\text { RR }\end{array}$ & $\begin{array}{c}95 \% \\
\mathrm{Cl}\end{array}$ & $\begin{array}{c}\text { Adjusted } \\
\mathrm{RR}^{\star}\end{array}$ & $\begin{array}{c}95 \% \\
\mathrm{Cl}\end{array}$ & $\begin{array}{c}\text { Crude } \\
\text { RR }\end{array}$ & $\begin{array}{c}95 \% \\
\mathrm{Cl}\end{array}$ & $\begin{array}{c}\text { Adjusted } \\
\mathrm{RR}^{\star}\end{array}$ & $\begin{array}{c}95 \% \\
\mathrm{Cl}\end{array}$ & $\begin{array}{c}\text { Crude } \\
\text { RR }\end{array}$ & $\begin{array}{c}95 \% \\
\mathrm{Cl}\end{array}$ & $\begin{array}{c}\text { Adjusted } \\
\mathrm{RR}^{\star}\end{array}$ & $\begin{array}{c}95 \% \\
\mathrm{Cl}\end{array}$ & $\begin{array}{c}\text { Crude } \\
\text { RR }\end{array}$ & $\begin{array}{c}95 \% \\
\mathrm{Cl}\end{array}$ & $\begin{array}{c}\text { Adjusted } \\
\mathrm{RR}^{\star}\end{array}$ & $\begin{array}{c}95 \% \\
\mathrm{Cl}\end{array}$ \\
\hline \multicolumn{17}{|l|}{$\begin{array}{l}\text { Fruit intake } \\
\text { (servings/d) }\end{array}$} \\
\hline $2-3$ & $0 \cdot 7$ & $0.5,0.98$ & $0 \cdot 7$ & $0 \cdot 5,1 \cdot 0$ & 0.9 & $0 \cdot 7,1 \cdot 4$ & $1 \cdot 0$ & $0 \cdot 7,1 \cdot 4$ & $1 \cdot 0$ & $0 \cdot 6,1 \cdot 7$ & $1 \cdot 0$ & $0 \cdot 6,1 \cdot 8$ & $1 \cdot 2$ & $0.7,1.9$ & $1 \cdot 2$ & $0 \cdot 7,1 \cdot 9$ \\
\hline$\geq 4$ & 0.5 & $0 \cdot 3,1 \cdot 1$ & 0.6 & $0 \cdot 3,1 \cdot 1$ & $1 \cdot 0$ & $0 \cdot 6,1 \cdot 7$ & $1 \cdot 0$ & $0 \cdot 6,1 \cdot 8$ & $1 \cdot 5$ & $0 \cdot 5,4 \cdot 3$ & $1 \cdot 6$ & $0 \cdot 5,4 \cdot 5$ & $0 \cdot 8$ & $0 \cdot 3,2 \cdot 1$ & $0 \cdot 8$ & $0 \cdot 3,2 \cdot 1$ \\
\hline \multicolumn{17}{|l|}{$\begin{array}{l}\text { Vegetable intake } \\
\text { (servings/d) }\end{array}$} \\
\hline $2-3$ & $0 \cdot 9$ & $0 \cdot 7,1 \cdot 2$ & 0.9 & $0 \cdot 7,1 \cdot 2$ & $0 \cdot 6$ & $0.4,0.8$ & 0.6 & $0 \cdot 4,0 \cdot 8$ & 0.9 & $0.5,1 \cdot 6$ & 0.9 & $0 \cdot 5,1 \cdot 6$ & $1 \cdot 1$ & $0 \cdot 7,1 \cdot 7$ & $1 \cdot 1$ & $0 \cdot 7,1 \cdot 7$ \\
\hline$\geq 4$ & $0 \cdot 8$ & $0 \cdot 4,1 \cdot 3$ & 0.8 & $0 \cdot 4,1 \cdot 4$ & $0 \cdot 7$ & $0 \cdot 4,1 \cdot 2$ & $0 \cdot 7$ & $0 \cdot 4,1 \cdot 2$ & $0 \cdot 7$ & $0 \cdot 2,2 \cdot 1$ & $0 \cdot 7$ & $0 \cdot 2,2 \cdot 2$ & $1 \cdot 1$ & $0 \cdot 4,2 \cdot 8$ & $1 \cdot 1$ & $0 \cdot 4,2 \cdot 7$ \\
\hline \multicolumn{17}{|l|}{ Smoking } \\
\hline Yes & $2 \cdot 0$ & $1 \cdot 5,2 \cdot 6$ & $1 \cdot 9$ & $1 \cdot 5,2 \cdot 5$ & $2 \cdot 8$ & $1 \cdot 9,4 \cdot 2$ & $2 \cdot 9$ & $1 \cdot 9,4 \cdot 2$ & $1 \cdot 6$ & $1 \cdot 0,2 \cdot 6$ & $1 \cdot 6$ & $0 \cdot 9,2 \cdot 8$ & $1 \cdot 2$ & $0 \cdot 8,1 \cdot 8$ & $1 \cdot 2$ & $0 \cdot 8,2 \cdot 1$ \\
\hline \multicolumn{17}{|l|}{$\begin{array}{l}\text { Smoking quartile } \\
\text { (cigarettes/d) }\end{array}$} \\
\hline $6-12$ & $1 \cdot 0$ & $0.7,1.5$ & $1 \cdot 1$ & $0 \cdot 8,1 \cdot 5$ & 0.9 & $0 \cdot 6,1 \cdot 3$ & 0.9 & $0 \cdot 6,1 \cdot 3$ & $2 \cdot 8$ & $0 \cdot 7,10 \cdot 5$ & $2 \cdot 9$ & $0 \cdot 8,10 \cdot 8$ & $0 \cdot 7$ & $0 \cdot 3,1 \cdot 7$ & $0 \cdot 7$ & $0 \cdot 3,1 \cdot 7$ \\
\hline $13-25$ & $1 \cdot 0$ & $0 \cdot 7,1 \cdot 4$ & $1 \cdot 1$ & $0 \cdot 8,1 \cdot 5$ & 0.9 & $0 \cdot 6,1 \cdot 2$ & 0.9 & $0 \cdot 6,1 \cdot 2$ & $2 \cdot 6$ & $0 \cdot 7,9 \cdot 4$ & $2 \cdot 6$ & $0 \cdot 7,9 \cdot 7$ & $1 \cdot 0$ & $0.5,2 \cdot 0$ & $1 \cdot 0$ & $0 \cdot 5,2 \cdot 0$ \\
\hline$\geq 28$ & $1 \cdot 2$ & $0 \cdot 7,2 \cdot 0$ & $1 \cdot 2$ & $0 \cdot 7,2 \cdot 2$ & $1 \cdot 1$ & $0 \cdot 7,1 \cdot 7$ & $1 \cdot 1$ & $0 \cdot 7,1 \cdot 7$ & NA & & NA & & $0 \cdot 6$ & $0 \cdot 1,2 \cdot 4$ & 0.5 & $0 \cdot 1,2 \cdot 3$ \\
\hline \multirow{2}{*}{\multicolumn{17}{|c|}{$\begin{array}{l}\text { Drinking } \\
\text { No }\end{array}$}} \\
\hline No & Reference & & & & & & & & & & & & & & & \\
\hline Yes & $1 \cdot 1$ & $0 \cdot 8,1 \cdot 4$ & $1 \cdot 0$ & $0 \cdot 8,1 \cdot 3$ & $1 \cdot 1$ & $0 \cdot 7,1 \cdot 7$ & $1 \cdot 1$ & $0 \cdot 8,1 \cdot 5$ & $1 \cdot 1$ & $0 \cdot 6,2 \cdot 0$ & $1 \cdot 0$ & $0 \cdot 5,1 \cdot 8$ & $0 \cdot 7$ & $0 \cdot 4,1 \cdot 1$ & 0.6 & $0 \cdot 3,1 \cdot 0$ \\
\hline \multicolumn{17}{|l|}{$\begin{array}{l}\text { Smoking and } \\
\text { drinking } \\
\text { None }\end{array}$} \\
\hline Smoking only & $2 \cdot 2$ & $1 \cdot 5,3 \cdot 3$ & $2 \cdot 1$ & $1 \cdot 4,3 \cdot 1$ & $2 \cdot 5$ & $1 \cdot 3,4 \cdot 7$ & $3 \cdot 3$ & $1 \cdot 4,7 \cdot 8$ & $1 \cdot 6$ & $0 \cdot 6,4 \cdot 0$ & $1 \cdot 5$ & $0 \cdot 6,3 \cdot 7$ & $1 \cdot 4$ & $0 \cdot 5,3 \cdot 9$ & $1 \cdot 3$ & $0 \cdot 5,3 \cdot 7$ \\
\hline Drinking only & $0 \cdot 8$ & $0.5,1 \cdot 3$ & $0 \cdot 8$ & $0 \cdot 5,1 \cdot 3$ & $0 \cdot 7$ & $0 \cdot 3,1 \cdot 3$ & 0.6 & $0 \cdot 3,1 \cdot 4$ & $0 \cdot 9$ & $0 \cdot 4,2 \cdot 1$ & $0 \cdot 8$ & $0 \cdot 3,2 \cdot 0$ & 0.5 & $0 \cdot 2,1 \cdot 1$ & 0.5 & $0 \cdot 2,1 \cdot 0$ \\
\hline Both & $1 \cdot 8$ & $1 \cdot 3,2 \cdot 5$ & $1 \cdot 7$ & $1 \cdot 2,2 \cdot 4$ & $2 \cdot 1$ & $1 \cdot 2,3 \cdot 5$ & $2 \cdot 6$ & $1 \cdot 3,4 \cdot 9$ & $1 \cdot 5$ & $0 \cdot 8,3 \cdot 0$ & $1 \cdot 3$ & $0 \cdot 6,2 \cdot 8$ & $0 \cdot 8$ & $0.5,1 \cdot 6$ & $0 \cdot 7$ & $0 \cdot 4,1 \cdot 4$ \\
\hline
\end{tabular}

$\mathrm{RCF}$, red-cell folate; NA, data not available.

Adjusted for age. 
In Australia, the most recent evaluation of the mandatory folate fortification programme in the diagnostic pathology laboratory of a large public hospital in New South Wales showed that the prevalence of low RCF decreased dramatically from $3 \cdot 4 \%$ to $0.5 \%$ between 2009 and 2010 among general patients and from $0 \cdot 45 \%$ to $0 \cdot 16 \%$ among female patients of childbearing age (15-50 years) between 2007 to $2009^{(33)}$. There should be an evaluation of the impact of this programme on high-risk populations, especially remote Indigenous populations, where healthy foods, and in particular fresh fruit and vegetables, are limited in quantity, of variable quality and expensive ${ }^{(34)}$. In addition, sales data from stores in remote Queensland Aboriginal and Torres Strait Islander communities indicate that rice, which is not enriched with folate, is consumed in greater quantities than bread $^{(35)}$. Furthermore, the focus on RCF in any evaluation of a fortification programme should be tempered by the importance of ensuring access to a nutritious diet including adequate fresh fruit and vegetables, especially given that folate supplementation in randomised controlled trials had no effect on reducing $\mathrm{CVD}^{(36)}$.

Among the lifestyle factors assessed in the present study, smoking was the strongest factor that was associated with RCF deficiency among Aboriginal adults. The effect size of the association among women and men in our study varied in the range $\mathrm{RR}=1.9-2.9$ which is similar to findings reported in the USA (RR = $1 \cdot 7-2 \cdot 4)^{(10,11)}$, although these studies included different potentially confounding covariates such as age, sex, race, socio-economic status, folate intake, vitamin use and alcohol use. In Australia overall, about half of Indigenous adults are current daily smokers. Results from the 1998-1999 household expenditure survey conducted by the Australian Bureau of Statistics suggested that smoking households were more likely to engage in unhealthy behaviours including spending on alcohol, drinking and gambling than non-smoking households and less likely to spend on health insurance and food ${ }^{(37)}$. Collecting data about both fruit and vegetable intake and smoking enabled us to study the relationships between smoking and fruit and vegetables on RCF status to better understand the underlying pathways for RCF deficiency. The association between smoking and low RCF was significant only in the Aboriginal population and not in Torres Strait Island people, who have different behavioural and metabolic profiles. One possible reason is that Aboriginal people had a higher prevalence of smoking and lower fruit and vegetable intake than Torres Strait Islanders, which may explain the difference. It is possible that factors other than those measured in our study are associated with low RCF in Torres Strait Islanders, and this deserves further investigation.

The fruit and vegetable intake data may have been measured with some error and may not adequately represent folate intake. Folate content of fruit and vegetables declines over time once harvested. The long food supply chains to these remote locations ${ }^{(38)}$ may mean that the fruit and vegetables available in these settings are not as rich in folate as produce available in mainstream settings.

\section{Conclusions}

The present study found a markedly higher prevalence of folate deficiency in a north Queensland Indigenous population than in the general Australian community. In particular, the highest prevalence of RCF deficiency was among younger people, especially women of childbearing age. The cohort was demographically representative of the indigenous population of the local area when compared with local population census data, therefore the result is generalisable to Indigenous populations in remote communities in north Queensland ${ }^{(18)}$. The impact of mandatory folate fortification programmes in this population should be evaluated, along with further efforts to reduce the rate of tobacco smoking.

\section{Acknowledgements}

The study was supported in part by the National Health and Medical Research Council (grant number 279402). The authors have no conflicts of interest to declare. M.L. conceived the research question, did data analysis and interpretation. R.M. was responsible for the study design. K.D. took part in data analysis and interpretation. D.L. conceived the research question. All authors contributed to manuscript preparation and approved the manuscript. The authors thank the health staff in the participating communities and the Aboriginal and Torres Strait Islander Health Councils for their support. They also would like to thank the AusDiab Research Committee for allowing the use of relevant data to compare with the RCF level found in the present study.

\section{References}

1. Health Promotion and Chronic Disease Prevention, Public Health Branch, Rural \& Regional Health \& Aged Care Services Division (2011) Folate - information for health professionals. Victorian State Government, Department of Health, Australia. http://www.health.vic.gov.au/nutrition/ folate/health_prof.htm (accessed August 2011).

2. Charlotte A, Gary M, Martha M et al. (2010) Folate status and birth defect risk - epidemiological perspective. In Folate in Health and Disease, 2nd ed., pp. 133-153 [B Lynn, editor]. New York: CRC Press, Taylor \& Francis Group.

3. Abu-Saad K \& Fraser D (2010) Maternal nutrition and birth outcomes. Epidemiol Rev 32, 5-25.

4. Hung J, Beilby JP, Knuiman MW et al. (2003) Folate and vitamin $\mathrm{B}_{12}$ and risk of fatal cardiovascular disease: cohort study from Busselton, Western Australia. BMJ 326, 131-136.

5. Voutilainen S, Virtanen JK, Tiina HR et al. (2004) Serum folate and homocysteine and the incidence of acute coronary events: the Kuopio Ischaemic Heart Disease Risk Factor Study. Am J Clin Nutr 80, 317-323. 
6. Larsson SC, Giovannucci E \& Wolk A (2007) Folate and risk of breast cancer: a meta-analysis. I Natl Cancer Inst 99, 64-76.

7. Sanjoaquin M, Allen N, Couto E et al. (2005) Folate intake and colorectal cancer risk: a meta-analytic approach. Int J Cancer 113, 825-828.

8. Jung Eun L, Walter CW, Charles SF et al. (2011) Folate intake and risk of colorectal cancer and adenoma: modification by time. Am J Clin Nutr 93, 817-825.

9. Okumura K \& Tsukamoto H (2011) Folate in smokers. Clin Chim Acta 412, 521-526.

10. Piyathilake CJ, Macaluso M, Hine RJ et al. (1994) Local and systemic effects of cigarette smoking on folate and vitamin B-12. Am J Clin Nutr 60, 559-566.

11. Mannino D, Mulinare J, Ford E et al. (2003) Tobacco smoke exposure and decreased serum and red blood cell folate levels: data from the Third National Health and Nutrition Examination Survey. Nicotine Tob Res 5, 357-362.

12. Halsted C, Medici V \& Esfandiari F (2010) Influence of alcohol on folate status and methionine metabolism in relation to alcoholic liver diseases. In Folate in Health and Disease, 2nd ed., pp. 429-448 [B Lynn, editor]. New York: CRC Press, Taylor \& Francis Group.

13. Coyne T, Ibiebele TI, McNaughton S et al. (2005) Evaluation of brief dietary questions to estimate vegetable and fruit consumption - using serum carotenoids and redcell folate. Public Health Nutr 8, 298-308.

14. Australian Institute of Health and Welfare (2010) Australia's Health 2010. Catalogue no. AUS 122. Canberra: AIHW.

15. Abeywardana S \& Sullivan EA (2008) Neural Tube Defects in Australia. An Epidemiological Report. Catalogue no. PER 45. Sydney: AIHW National Perinatal Statistics Unit.

16. Mclean E, de Benoist B \& Allen LH (2008) Review of the magnitude of folate and vitamin $\mathrm{B}_{12}$ deficiencies worldwide. Food Nutr Bull 29, 2 Suppl., S38-S50.

17. Shane B (2010) Folate chemistry and metabolism. In Folate in Health and Disease, 2nd ed., pp. 1-22 [B Lynn, editor]. New York: CRC Press, Taylor \& Francis Group.

18. Miller G, McDermott R, McCulloch B et al. (2002) The Well Person's Health Check: a population screening program in indigenous communities in north Queensland. Aust Health Rev 25, 136-147.

19. Australian Bureau of Statistics (1998) National Nutrition Survey: Nutrient Intakes and Physical Measurements, Australia, 1995. Catalogue no. 4805.0. Canberra: ABS.

20. Harada N, Chiu V, King A et al. (2001) An evaluation of three self-report physical activity instruments for older adults. Med Sci Sports Exerc 33, 962-970.

21. Attebring M, Herlitz J, Berndt A et al. (2001) Are patients truthful about their smoking habits? A validation of selfreport about smoking cessation with biochemical markers of smoking activity amongst patients with ischemic heart disease. I Int Med Res 249, 145-151.

22. Dunstan D, Zimmet P, Welborn T et al. Australian Diabetes, Obesity and Lifestyle Study (AusDiab) (2002) The Australian Diabetes, Obesity and Lifestyle Study (AusDiab) - methods and response rates. Diabetes Res Clin Pract 57, 119-129.

23. World Health Organization (1998) Obesity: Preventing and Managing the Global Epidemic. Report of a WHO Expert Committee. WHO Technical Report Series no. 894. Geneva: WHO.
24. World Health Organization (1999) Diagnosis and Classification of Diabetes Mellitus. Definition, Diagnosis and Classification of Diabetes Mellitus and Its Complications. Geneva: Department of Non-communicable Disease Surveillance, WHO.

25. Australia Diabetes Society (1995) Diabetic dyslipidemia Australian Diabetes Society position statement. Med J Aust 162, 91-93.

26. Li M \& McDermott RA (2010) Using anthropometric indices to predict cardio-metabolic risk factors in Australian indigenous populations. Diabetes Res Clin Pract 87, 401-406.

27. Australian Bureau of Statistics \& Australian Institute of Health and Welfare (2008) The Health and Welfare of Australia's Aboriginal and Torres Strait Islander Peoples 2008. ABS Catalogue no. 4704.0, AIHW Catalogue no. IHW 21. Canberra: ABS and AIHW.

28. Giskes K, Turrell G, Patterson C et al. (2002) Socioeconomic differences among Australian adults in consumption of fruit and vegetables and intake of vitamins A, C and folate. J Hum Nutr Diet 15, 375-385.

29. Food Standards Australia New Zealand (2009) Mandatory folic acid fortification in Australia. http://www.foodstandards. gov.au/_srcfiles/Mandatory20\%Folic20\%Acid20\%Fortification 20\%User20\%Guide20\%final.pdf (accessed August 2011).

30. Hickling S, Hung J, Knuiman M et al. (2005) Impact of voluntary folate fortification on plasma homocysteine and serum folate in Australia from 1995 to 2001: a population based cohort study. J Epidemiol Community Health 59, 371-376.

31. Berry R, Mulinare J \& Hamner H (2010) Folate acid fortification-neural tube defect risk reduction - a global perspective. In Folate in Health and Disease, 2nd ed., pp. 429-448 [B Lynn, editor]. New York: CRC Press, Taylor \& Francis Group.

32. Colapinto C, O'Connor D \& Tremblay M (2011) Folate status of the population in the Canadian Health Measures Survey. CMAJ 183, E100-E106.

33. Brown R, Langshaw M, Uhr E et al. (2011) The impact of mandatory fortification of flour with folic acid on the blood folate levels of an Australian population. Med J Aust 194, 65-67.

34. Harrison M, Lee A, Findlay M et al. (2010) The increasing cost of healthy food. Aust N Z J Public Health 34, 179-186.

35. Gregoriou A \& Leonard D (2010) RIST: Evaluation of the Remote Indigenous Stores and Takeaways Resources in Queensland and the Anangu Pitjantjatjara Yankunytjatjara Lands of South Australia, pp. 77-78. Cairns: Queensland Health.

36. Bazzano L, Reynolds K, Holder K et al. (2006) Effect of folic acid supplementation on risk of cardiovascular diseases. JAMA 296, 2720-2726.

37. Siahpush M, Borland R \& Scollo M (2004) Is household smoking status associated with expenditure on food at restaurants, alcohol, gambling and insurance? Results from the 1998-99 household expenditure survey, Australia. Tob Control 13, 409-414.

38. Leonard D, Beilin R \& Moran M (1995) Which way kaikai blo umi? Food and nutrition in the Torres Strait. Aust $J$ Public Health 19, 589-595. 